\title{
Educação Infantil em tempo integral: implicações da política de extensão da jornada escolar das crianças da cidade de Janaúba/MG
}

\author{
Full-time early childdhood education: implications of the policie of extension of the children's school \\ day from Janaúba/MG
}

L'éducation à temps plein au Brésil: implications de la politique de la prolongation de la journée scolaire des enfants de la ville de Janaúba/MG

\author{
Ediléia Alves Mendes Souza ${ }^{1}$ \\ Universidade Estadual de Montes Claros \\ Clésia Lorrany Soares Araújo² \\ Rede Municipal de Ensino de Janaúba/MG
}

\begin{abstract}
Resumo: Neste trabalho o objetivo foi analisar implicações da política de educação de tempo integral para o processo ensino aprendizagem na educação infantil no CEMEI "X" da cidade de Janaúba-MG. Nessa pesquisa de cunho qualitativo numa perspectiva exploratória, se desenvolveu pesquisa bibliográfica, utilizando-se de autores como Kuhlman Jr. (2010), Cavaliere (2002), Coelho (2009), Gadotti (2009); e no campo empírico, obteve-se os dados por meio da aplicação de um questionário com questões objetivas e discursivas às oito professoras participantes. As informações foram organizadas e interpretadas à luz do referencial teórico. Com base nos resultados é possível afirmar que as professoras identificaram e vivenciaram vários desafios na instituição, entre eles, escassez de recursos humanos e materiais, cansaço das crianças, falta de estrutura da escola e ausência dos pais. Para elas, esses fatores interferem na realização do trabalho pedagógico, o que vem afetando a aprendizagem e desenvolvimento das crianças.
\end{abstract}

Palavras-chave: Educação infantil. Políticas de Educação em tempo integral. Escola de tempo integral. Ensino-aprendizagem.

\begin{abstract}
In this paper the objective was to analyze implications of integral education policies for the teaching-learning process in early childhood education at CEMEI "X" from Janaúba-MG. In this qualitative research from an exploratory perspective, bibliographical research was developed, using authors such as Kuhlman Jr. (2010), Cavaliere (2002), Coelho (2009), Gadotti (2009). In the empirical field, the data were obtained by applying a questionnaire with objective and discursive questions to the eight participating teachers. The information was organized and interpreted according to the theoretical background. Based on the results, it is possible to affirm that the teachers identified and experienced several challenges in the institution, among them, scarcity of human and material resources, children fatigue, lack of school structure and absence of parents. For them, these factors interfere in the development of pedagogical work, which has been affecting the learning and devlopment of the children.
\end{abstract}

Key words: Early childhood education. Integral education policies. Integral school. Teaching-learning.

${ }^{1}$ Doutora em Educação/UFU; Mestre em Educação/UnB; Professora do DMTE/Unimontes; E-mail: edileia_mendes@yahoo.com.br. ORCID: https://orcid.org/0000-0001-9369-2453. Lattes: http://lattes.cnpq.br/4349292205055105.

${ }^{2}$ Licenciada em Pedagogia/Unimontes; clesialorrany@bol.com.roRCID:

Professora da Rede Municipal de Janaúba/MG. E-mail: http://lattes.cnpq.br/8963212276511968. https://orcid.org/0000-0002-3171-6998. Lattes: 
Résumé: Dans cet article, l'objetif a été analyser implications de la politique l'éducation à temps integral pour le procédé d'enseignement et apprentissage dans l'éducation des enfants au CEMEI "X" de la ville Janaúba-MG. Au point de vue exploratoire, cet étude qualitative a été développé à partir de auteurs comme Kuhlman Jr. (2010), Cavaliare (2002), Coelho (2009), Gadotti (2009). Pour le empirique terrain, les donnés ont été obtenus parmi de la application d'un questionnaire avec des questions objectives et discursives aux huit enseignants participants. Les informations ont éte organizées et interprétées avec les idées du cadre théorique. Selon les résultáts, il est possible noter que les enseignants ont identifié et vécu plusieurs défis dans l'institution, entre eux, le manque de ressources humaines et matérielles, l'épuisement des enfant, le manque de structure scolaire et l'absence de parents. Pour elles, ces facteurs interfèrent dans le développement du travail pédagogique. Cela affecte l'apprentissage et le développement des enfants.

Mots-Clés: Éducation des enfants. Politiques d'éducation à plein temps. École à plein temps. Enseignement et apprentissage.

Recebido em: 5 de Dezembro de 2019 Aceito em: 03 de janeiro 2020

\section{Introdução}

Com a crescente inserção das mulheres no mercado de trabalho e a realidade de pais que precisam trabalhar o dia todo, a Educação em Tempo Integral (ETI) ministrada nas escolas tornou-se uma alternativa plausível visto que, para muitos pais, neste espaço os filhos recebem cuidados e ficam protegidos dos perigos das ruas. Ressalta-se que, independente do motivo pelo qual a criança esteja inserida no horário integral escolar, todas merecem e têm direito a uma educação de qualidade.

Este trabalho de natureza qualitativa e de caráter exploratório foi realizado no ano de 2016 e teve como objetivo geral analisar as implicações da política de educação de tempo integral no processo ensino aprendizagem na educação infantil no Centro Municipal de Educação Infantil X (CEMEI X) da cidade de Janaúba-MG na visão de professores da instituição. Essa instituição atendia ao maior número de turmas com período integral, sendo esse o critério que definiu sua seleção para realização da pesquisa. As professoras foram aquelas que atuavam em duplas (uma no matutino e uma no vespertino) nas mesmas turmas.

No trabalho de investigação utilizou-se de procedimentos como a pesquisa bibliográfica, baseada em autores como Kuhlman Jr. (2010), Cavaliare (2002), Coelho (2009) dentre outros. A obtenção dos dados empíricos concentrou-se na leitura atenta do Projeto Político Pedagógico (PPP) da escola para levantamento de informações relativas à instituição e à aplicação de um questionário com questões objetivas e discursivas com a participação de 
oito professoras. Essas participantes foram denominadas de P1 a P8 e a escola de CEMEI X, como formas de garantir a proteção de suas identidades.

O artigo está estruturado em duas seções, na primeira apresenta-se o arcabouço teórico com os principais conceitos e na segunda a análise dos dados construídos com a participação das professoras atuantes na educação infantil de tempo integral.

\section{Educação infantil e políticas de educação em tempo integral: uma realidade no sistema público de educação brasileiro}

Ao longo dos anos a educação infantil entre rupturas e permanências passou por mudanças tanto de ordem conceitual quanto da prática pedagógica. No Brasil, a própria concepção de educação infantil, conforme Oliveira (2011), começou a ganhar destaque a partir da segunda metade do Século XIX, período da abolição da escravatura e da proclamação da República, no qual se acentuou a migração para as grandes cidades e o desenvolvimento cultural e tecnológico. Nesse contexto, as instituições de educação infantil, de caráter assistencialista, representavam uma alternativa viável e oficialmente autorizada de retirar as crianças das ruas, sobretudo as escravas, amenizando assim um incômodo social.

No Brasil, assim como nos países europeus, os relatos das primeiras creches estão associados ao movimento operário e às necessidades das famílias relacionadas ao crescimento da urbanização, à industrialização e à transformação da família patriarcal em nuclear. Oliveira (2011, p.43) salienta que a creche vem sendo historicamente vista como "refúgio assistencial para a população infantil desprovida de cuidados domésticos, tem definido a infância como uma questão de ordem privada e não tem considerado devidamente a comunidade maior como corresponsável pela educação dos pequenos”.

Kuhlman Jr. (2010) ressalta que no início do século XX implantaram-se as primeiras instituições pré-escolares no Brasil e, ao contrário do que aconteceu na Europa, aqui primeiro fundaram-se as creches e, posteriormente, os jardins de infância. Essa ideia gerou acirrados debates à época, muitos criticavam ao fazerem identificação dessas instituições com as salas de asilo francesas, entendidas como locais de mera guarda de crianças, outros a defendiam por acreditarem que trariam vantagens para o desenvolvimento infantil sob a influência do movimento escolanovista.

A partir da Constituição Federal de 1988 a educação foi conquistada como direito de todos os cidadãos brasileiros, como decorrência, a educação infantil passou a fazer parte dos deveres do Estado. Conforme Kuhlman (2010) se a creche passa a fazer parte do sistema 
educacional, ela deixa de ser apresentada apenas como alternativa para pobres incapazes, para ser posta como complementar à ação da família, tornando-se uma instituição legítima. Na Lei de Diretrizes e Bases da Educação Nacional, a LDB 9394/1996,

Art. 29 A educação infantil, primeira etapa da educação básica, tem como finalidade o desenvolvimento integral da criança de até 5 (cinco) anos, em seus aspectos físico, psicológico, intelectual e social, complementando a ação da família e da comunidade. (BRASIL, 1996, Redação dada pela Lei n 12.796, de 2013).

Partindo da premissa de formação integral, na viabilização do processo ensino aprendizagem vários elementos são colocados em movimento e, neste sentido, não apenas aos recursos ou métodos que se utiliza carecem de atenção, mas se esses estão adequados à realidade, à faixa etária, aos interesses, ao contexto e se dizem respeito às necessidades das crianças. Souza (2012) argumenta que a finalidade da educação infantil com a formação integral das crianças coloca em movimento aspectos indissociáveis, por isso,

[...] a proposta pedagógica, o planejamento e a prática docente, como
elementos que viabilizam a concretização do trabalho pedagógico na escola,
podem potencializar a realização de um trabalho de qualidade se se
constituírem numa articulação coerente com as concepções da educação de
tempo integral, que coloca em movimento professores, coordenadores e
gestores cuja mobilização para as atividades seja pautada pelo compromisso
ético e político com o projeto educativo (SOUZA, 2012, p.57).

Mas, de qual projeto educativo? Essa é uma questão que não pode ficar de fora na construção das propostas pedagógicas visto que este documento traduz a realidade, os anseios e sonhos da comunidade escolar e registra parte significativa da concepção de ensinoaprendizagem assumida pela instituição.

Nessa conjuntura, a ETI tem sido uma realidade no sistema público de ensino do Brasil que, às vezes, não é entendida nem pelos próprios profissionais das escolas. As atividades realizadas são as mesmas que se realizaria em uma escola de jornada regular sem se preocuparem com a formação integral. Muitas vezes a ampliação da jornada escolar é vista como uma forma de manter as crianças fora das ruas, dando-lhes assistência, todavia apesar de o horário ser integral é como se a educação não fosse. Esses fatores denunciam a fragilidade na execução da política de educação infantil de tempo integral ao fragmentar o processo educativo numa clara dicotomia entre o educar, o brincar e o cuidar, a tríade inseparável nessa etapa educativa.

Para se entender alguns conceitos que envolvem a ETI, faz-se necessário analisar o contexto histórico em que a integralidade da formação humana se evidenciou como uma necessidade não somente de compreensão da interação mente/corpo, matéria/espírito, mas 
da importância que assume uma educação consistente no seu mais amplo sentido para as transformações sociais. Novas demandas e anseios requerem novos modelos educacionais com mais igualdade de oportunidades, para tal a implementação de políticas de ETI tornaram-se uma realidade premente.

Gallo (2002) salienta que a educação integral como articulação social foi desenvolvida durante o movimento operário francês, caracterizado por um conjunto de tentativas coletivas de alterar a ordem social e econômica como formas de melhorar as condições de vida da população operária desde a Revolução Francesa. Esse período redundou em consolidação da sociedade burguesa na qual os trabalhadores assalariados lutaram, e continuam lutando, para conseguir que o Estado forneça um sistema educacional que propricie maiores e melhores oportunidades para o operariado e seus filhos.

Nessa direção relata Oliveira (2011) que no Brasil, sendo de propriedade de sociedade privada, as creches e as demais instituições sociais eram usadas pelas empresas no ajuste das relações de trabalho e entendidas como um "mal necessário". As creches eram planejadas como instituições de saúde, com rotinas de triagem, lactário, pessoal auxiliar de enfermagem, preocupação com higiene do ambiente físico. Desse modo, "creches e parques infantis que atendiam crianças em período integral passaram a ser cada vez mais procuradas não só por operários e empregadas domésticas, mas também por trabalhadores do comércio e funcionárias públicas” (OLIVEIRA, 2011 , p.102).

Ante as demandas sociais, o movimento Escolanovista nos anos 1930, encabeçado por Anísio Teixeira, um progressista que influenciou o campo educacional com novos conceitos de educar, contribuiu de modo determinante para a instalação das escolas de tempo integral no Brasil (CHAVES, 2002). Essas escolas passaram a ser uma necessidade por serem locais nos quais os pais poderiam deixar seus filhos em segurança para irem trabalhar. Todavia, há de se considerar que, "a escola de tempo integral precisa evoluir de uma necessidade para uma escolha, de modo que, um dia, os pais não precisem do horário integral para seus filhos, mas que o desejem” (MACHADO, 2002, p.227).

De acordo com a LDB/1996, a educação integral é o aumento progressivo da jornada escolar na direção do regime de tempo integral, valorizando as iniciativas educacionais extraescolares e a vinculação entre o trabalho escolar e a vida em sociedade. Nesse sentido, não basta criar escolas de tempo integral, é necessário que se propicie oportunidades e espaços adequados para o desenvolvimento da educação integral.

Nesta linha de raciocínio Coelho (2002) argumenta que uma escola que funcione em tempo integral não pode ser apenas uma escola de dupla jornada com repetição de tarefas e 
metodologias. Desse modo, assim como afirma Machado (2002), a escola de horário integral pode se tranformar em um ambiente confuso e enfadonho, onde crianças e professores, sem condições para desenvolver um trabalho diversificado e rico, passem ao tédio, ao sofrimento, à agressividade, ao desinteresse em sua permanência na escola.

Em decorrência desse aspecto, torna-se urgente a "renovação da aposta na perspectiva da educação integral como forma de desenvolvimento integral da pessoa humana e construção de cidadania” (PACHECO, 2008, p.26). Essa proposta articulada a um projeto de cidadania se vincula intimamente ao Projeto Político Pedagógico da escola construído democraticamente, com a participação da comunidade, de pais e alunos. Azevedo (2003, p. 232) argumenta que "a escola é por excelência, por determinação histórica e social, um espaço de educação. Tudo nela educa, todos nela educam e são educados”. Por isso ao se pensar no funcionamento de uma escola de tempo integral, é essencial rever todo o processo, desde as metodologias adotadas até a avaliação.

Machado (2002) aponta que as famílias se constituem em elos essenciais e que buscar na educação infantil de tempo integral não apenas banho, uniforme, material e comida, mas, sobretudo uma educação de qualidade para seus filhos, visto ser esse um dever do Estado e direito das famílias e crianças que necessitam serem acolhidas e construirem uma aprendizagem significativa associada ao conhecimento científico, social e cultural visando, assim, atingir a formação integral.

Gadotti (2009) afirma que a educação integral não deve ser confundida com escolarização, pois a escola não é a única instituição que possibilita o desenvolvimento de potencialidades humanas, de forma que a educação integral acontece durante toda a vida e em "todos os cantos”. Ressalta que todas as escolas precisam ser de educação integral, mesmo que não sejam de tempo integral, trata-se de oferecer mais oportunidades de aprendizagem para todos os alunos. Sendo então o princípio geral da educação integral a omnilateralidade e não a parcialidade e a fragmentação. Esse princípio afirma a educação integral como educação com qualidade sociocultural, em que o conceito de integralidade se constitui em princípio organizador do currículo escolar, de modo a proporcionar a integração de todos os conhecimentos de forma interdisciplinar, intercultural e transversal, baseando a aprendizagem nas vivências dos alunos.

A discussão da educação integral e da escola de tempo integral precisa partir de novos pressupostos, de uma teoria da educação que leve em conta a globalização e a impregnação contemporânea da informação (GADOTTI, 2009). Para esse autor a educação integral não é apenas mais uma opção pela qualidade da educação, um projeto entre outros projetos, mas sim 
um dever do Estado e um direito dos cidadãos. Nesse sentido, Maurício (2002) afirma que a educação integral reconhece a pessoa como um todo e não como um ser fragmentado e que esta integralidade se constrói através de linguagens diversas em variadas atividades e circunstâncias.

Souza (2012) aponta que o termo educação integral se refere ao tempo social, aos aspectos da formação humana multidimensional, relacionado à qualidade das atividades desenvolvidas e o termo escola de tempo integral, horário integral, extensão/ampliação da jornada referem-se ao tempo cronológico, à carga horária diária que os alunos ficam no ambiente escolar ou em atividades coordenadas pela escola.

Sendo assim, para que haja uma relação ensino-aprendizagem de qualidade na educação infantil de tempo integral é necessário que se compreenda os diferentes contextos, fazendo com que a ampliação da jornada escolar não seja empecilho para o desenvolvimento integral da criança e nem justificativa para práticas pedagógicas descontextualizadas.

A partir de 2007, por meio da Portaria Interministerial $n^{\circ} 17 / 2007$ que instituiu o Programa Mais Educação no segundo mandato do então Presidente Luiz Inácio Lula da Silva (2003-2011), a ETI passaria por outro momento. Nesse ínterim foram publicados diversos documentos para formalizarem o programa e materiais para direcionarem o trabalho nas escolas. No manual operacional citado abaixo, o Ministério da Educação (MEC) e a Secretaria de Educação Básica (SEB) junto à diretoria de currículos e educação integral reúne leis e diretrizes para a educação integral e define alguns dos principais marcos dessa política pública.

A educação integral está presente na legislação educacional brasileira e pode ser apreendida em nossa Constituição Federal, nos artigos 205, 206 e 227; no Estatuto da Criança e do Adolescente (Lei n 9089/1990); na Lei de Diretrizes e Bases (Lei $n^{\circ}$ 9394/1996), nos artigos 34 e 87; no Plano Nacional de Educação (Lei $n^{\circ}$ 10.179/01) e no Fundo Nacional de Manutenção e Desenvolvimento do Ensino Básico e de Valorização do Magistério (Lei $\left.n^{\circ} 11.494 / 2007\right)$. Por sua vez, a Lei $n^{\circ} 10.172$, de 9 de janeiro de 2001, que instituiu o Plano Nacional de Educação (PNE), retoma e valoriza a Educação Integral como possibilidade de formação integral da pessoa. O PNE avança para além do texto da LDB, ao apresentar a educação em tempo integral como objetivo do Ensino Fundamental e, também, da Educação Infantil. Além disso, o PNE apresenta, como meta, a ampliação progressiva da jornada escolar para um período de, pelo menos, 7 horas diárias, além de promover a participação das comunidades na gestão das escolas, incentivando o fortalecimento e a instituição de Conselhos Escolares (BRASIL, 2013, p. 04).

Nesse manual indicam-se duas relevantes políticas, a Lei $n^{\circ} 11.494$, de 20 de junho de 2007 e o Decreto $n^{\circ}$ 6.094/07, a partir das quais se instituiu o Fundo de Manutenção e Desenvolvimento da Educação Básica e de Valorização dos Profissionais da Educação (FUNDEB) que regulamenta a educação básica em tempo integral e os anos iniciais e finais 
do ensino fundamental $\left(\operatorname{art} .10, \S 3^{\circ}\right)$, formalizando que a legislação decorrente deverá normatizar essa modalidade de educação.

Posteriormente, no Decreto $n^{0}$ 6.253/07 definiu-se como educação básica em tempo integral a jornada escolar com duração igual ou superior a sete horas diárias, durante todo o período letivo, compreendendo o tempo total que um mesmo estudante permanece na escola ou em atividades escolares. A partir do Decreto $n^{\circ}$ 6.094/07, com o Plano de Metas Compromisso Todos pela Educação firmou-se o objetivo de produzir um conjunto de medidas visando a melhoria da qualidade da educação básica com a conjugação de esforços da União, estados, Distrito Federal e municípios, atuando em regime de colaboração.

No mais recente Plano Nacional de educação por intermédio da Lei 13.005/2014 (BRASIL, 2014) no governo da então Presidenta Dilma Vana Rousseff (2011 a 31 de agosto de 2016), foram traçadas metas e estratégias para a educação em tempo integral. Na meta 6 (seis) está prevista a oferta de educação em tempo integral em, no mínimo, 50\% (cinquenta por cento) das escolas públicas, de forma a atender, pelo menos, $25 \%$ (vinte e cinco por cento) dos (as) alunos (as) da educação básica. Entre as nove estratégias previstas estão: instituir, em regime de colaboração, programa de construção de escolas com padrão arquitetônico e de mobiliário adequado para atendimento em tempo integral, prioritariamente em comunidades pobres ou com crianças em situação de vulnerabilidade social; institucionalizar e manter, em regime de colaboração, programa nacional de ampliação e reestruturação das escolas públicas, por meio da instalação de quadras poliesportivas, laboratórios, inclusive de informática, espaços para atividades culturais, bibliotecas, auditórios, cozinhas, refeitórios, banheiros e outros equipamentos, bem como da produção de material didático e da formação de recursos humanos para a educação em tempo integral.

As políticas são instituídas, porém a realidade é dinâmica e no movimento histórico concreto ocorrem mudanças que ao implicar em descontinuidades podem afetar a operacionalização e efetividade das propostas, visto serem, muitas vezes, de governo e não de Estado. Neste sentido, as políticas ao serem implementadas não garantem por si mesmas um adequado desenvolvimento, por isso ressalta-se que na ampliação da jornada escolar, segundo a observação de Chaves (2002, p.43), "a qualidade do ensino/aprendizagem liga-se tanto à quantidade do tempo diário de escolarização quanto à possibilidade da escola oferecer muito mais do que o simples aprender a ler, escrever e contar”. Por isso, é importante a escola proporcione ao aluno um ensino no qual a aprendizagem esteja além daquilo que se consegue perceber em sala de aula, possibilitando que se estenda ao convívio social. 


\title{
2. Política de educação de tempo integral e suas implicações no contexto da educação infantil: percepções e experiências das professoras do CEMEI X de Janaúba/MG
}

Na cidade de Janaúba fica localizada no Norte do estado de Minas Gerais, no que pauta à legislação municipal, no ano de 2004, a Lei 1.589 definiu requisitos necessários para que os programas educacionais atendessem aos dispostos previstos no Estatuto da Criança e do Adolescente (ECA) assim como aos da LDB. Definiu-se também a integração das creches, que eram precariamente conveniadas, ao sistema municipal de educação.

A partir dessa lei instituiu-se como dever da Prefeitura zelar pela educação infantil incluindo os centros municipais de educação integral, iniciando o processo de desvinculação da educação infantil do setor de assistência social para o educacional. Na lei aponta-se um período de transição no processo composto pela integração das creches e dos centros de convivência infantil ao programa municipal de ensino, pelo reconhecimento das creches e escolas municipais de educação infantil como centros de educação infantil, funcionando em período integral ou parcial, conforme a opção dos pais ou responsáveis legais dos educandos.

Nesse contexto insere-se o CEMEI X que fica localizado em um bairro periférico da cidade de Janaúba/MG e atende a Educação Infantil com período regular e integral. Conforme o Projeto Político Pedagógico (PPP, 2015) a instituição foi fundada com objetivo de atender às crianças carentes e às mães que precisavam trabalhar fora de casa.

\begin{abstract}
A instituição atende alunos de família que são de baixa renda, algumas desestruturadas, algumas mães trabalham em casa de família, os pais são pedreiros, pintores, guardas, lavradores, autônomos e alguns estão desempregados. A grande maioria de nossas crianças vivencia em seu meio o uso de drogas, prostituição, violência e roubo. Outras não têm a paternidade assumida ou foram abandonadas pelas mães sendo criados pelas avós. É notório que a maioria dessas famílias são presentes na vida de seus filhos, participam bem das reuniões escolares, atende ao convite da escola para comparecer no momento das necessidades. Seus anseios são: garantir uma boa educação para seus filhos com segurança, que a escola atenda a criança com qualidade tanto na educação quanto na alimentação tendo cuidados tanto no aspecto físico como no afetivo (PPP, 2015, p.11).
\end{abstract}

A instituição originou-se da nucleação de pequenas creches dos bairros vizinhos que funcionavam em estado precário em casas alugadas. Desde 2003 passou a ser mantido pela Secretaria Municipal de Educação e não mais pela Secretaria de Promoção Social. No período da pesquisa em 2016, o CEMEI atendia um total de 320 crianças na faixa etária de 1 a 5 anos, distribuídos em 11 turmas de período regular e 04 turmas de período integral. 
A escola não dispunha de sede própria, dividia um espaço cedido pela Secretaria de Promoção Social com o Programa de Erradicação do Trabalho Infantil (PETI). O espaço físico da instituição era amplo e arejado, mas, de acordo com o PPP, não era suficiente para atender às demandas cotidianas necessitando de melhorias estruturais como salas para as crianças do berçário e computadores para atendimento à comunidade.

Durante a pesquisa foi possível perceber que apesar de os banheiros terem sido reformados, eram frequentes as reclamações de professores e auxiliares de turma que alegavam falta de espaço para os banhos coletivos e falta de manutenção nos chuveiros, visto que estava funcionando apenas um chuveiro no banheiro feminino com água fria. Havia queixas com relação à falta de armários, ventiladores, computadores, brinquedos, mesas para professores, berços, lençóis, uniformes, berçários adaptados, arquivos, prateleiras, além da falta de cobertura na quadra.

A entrada das crianças que vinham de ônibus acontecia desde às 6 h e $20 \mathrm{~min}$ da manhã quando chegava o primeiro veículo vindo de regiões mais distantes, em seguida outro de bairros mais próximos. Estas crianças eram recebidas pelas auxiliares de classe e ficavam esperando para ir para a sala de aula até as 7 horas quando chegavam as professoras. Algo preocupante nesses ônibus era a falta de segurança, as crianças eram transportadas sem cinto, algumas sentadas e outras em pé, pois o veículo andava sempre cheio visto que transportava crianças de outras escolas. As demais, que não vinham nos ônibus, chegavam conduzidas por seus pais e familiares, mas nem sempre cumpriam o horário, extrapolando, às vezes, às nove horas da manhã.

Na rotina, na medida em que as crianças chegavam à sala, a auxiliar de classe realizaria a troca de roupas, tirava a que as crianças tinham vindo de casa e colocava o uniforme que ficava na escola. Após esse momento, a professora colocava as cadeiras em círculo, realizava a oração diária e cantava músicas infantis com as crianças. Em seguida, no refeitório, tomavam o café da manhã, que geralmente era suco, iogurte ou leite com bolachas, pão ou bolo.

Ao voltarem do refeitório, realizavam atividades em sala de aula conforme o horário previsto. Logo após, das 10h às 10h:30min, geralmente acontecia o intervalo em um espaço em frente à sala de aula, onde havia um escorregador e um balanço de ferro inadequados à faixa etária, como não forneciam segurança elas ficavam correndo e brincando com terra, folhas e pedrinhas.

Às 10h e 30min, era servido o almoço para as crianças no refeitório e, em seguida elas se dirigiam à sala para o momento do sono em colchonetes disponibilizados por uma auxiliar. Às 11 horas, a professora regente terminava seu turno e a auxiliar ficava sozinha com as crianças até a outra auxiliar do turno vespertino chegar às $11 \mathrm{~h}$ e $30 \mathrm{~min}$. 
Ao meio-dia, as duas auxiliares acordavam as crianças para o banho, primeiro as meninas tomavam banho juntas, depois os meninos. Esse momento durava cerca de 30 minutos. A auxiliar do turno matutino ia embora às $12 \mathrm{~h}$ e 30 min e a auxiliar do turno vespertino terminava de pentear os cabelos das crianças, as quais aguardavam em rodinha a chegada da professora do turno vespertino às 13 horas.

Essa rotina quase que mecanicamente repetida envolvia todas as turmas, com exceção das crianças do berçário, visto que o banho era dado conforme a necessidade dos bebês, com organização, mas sem rigidez no cumprimento de horários.

No turno vespertino, no início da aula, a professora de modo genérico contava uma história, cantava ou colocava músicas infantis para as crianças escutarem e dançarem. Às $13 \mathrm{~h}$ e 30min, se dirigiam ao refeitório onde faziam um lanche, que, na maioria das vezes, era suco com bolacha ou bolo. Em seguida, brincavam um pouco no escorregador de plástico que ficava ao fundo do refeitório, mas como havia só um para muitos alunos, não era sempre que a professora os deixava brincar.

No quadro de horários da escola, constava que, na segunda-feira, deveriam ser realizadas oficinas de sucatas com as crianças, mas, em geral não ocorriam, de modo que, na maioria das vezes, faziam atividades em folhas xerografadas, pintando e colorindo desenhos. Na terça-feira, era dia da aula de educação física, mas como a quadra não era coberta, as aulas ocorriam na própria sala de aula.

Quarta-feira era o dia das brincadeiras pedagógicas, mas como na escola os recursos eram parcos, as crianças brincavam com uma caixa de brinquedos que ficava na sala de aula que continha alguns carrinhos, bonecas e outros, muitos deles danificados. Na quinta estava previsto filosofia para crianças junto com a contação de histórias e, na sexta-feira, psicomotricidade junto com oficinas de sucata, mas que também acabavam se restringindo a atividades para colorir e pintar. Após a realização dessas atividades era o momento de os alunos que traziam lanche de casa, lancharem e, em seguida, brincavam.

Às quatro e meia servia-se o jantar no refeitório de acordo com o cardápio que variava de arroz com frango desfiado, a feijoada, sopa e outros. Depois do jantar, se procedia à organização para a saída. O horário do final da aula era às 17 horas, os alunos que vinham de ônibus só saiam às 17 h e 30 min, mas o ônibus quase sempre se atrasava.

$\mathrm{Na}$ organização da rotina fica evidente a fragmentação do trabalho pedagógico entre os turnos, entre as professoras e entre as próprias crianças. Outro dado relevante é a escassez de auxiliares para os momentos do sono/descanso e da higienização/banho das crianças. Como proporcionar o desenvolvimento integral nesses momentos nos variados aspectos da 
formação infantil? Das diferentes linguagens? Da imagem de si mesmas, do esquema corporal e outros conhecimentos essenciais?

As condições concretas da estrutura, assim como dos materiais disponibilizados, se constituíam em um limitador na dimensão curricular, visto que havia o currículo oficialmente organizado, mas que na prática não ocorria de fato comprometendo assim as atividades e o desenvolvimento e a aprendizagem das crianças.

Esses fatores denunciam a precarização no desenvolvimento da ETI no CEMEI X. Nesse sentido, fortalece-se a necessidade de se discutir essa política e, desse modo, repensar as condições de sua viabilização no 'chão' da escola. Caso seja uma demanda social relevante deve ser ofertada com a devida estruturação, principalmente por se tratar de um atendimento direcionado, sobretudo às camadas populares, justamente aquela que mais precisa de melhores condições de oportunidades educacionais.

No que diz respeito às professoras todas se declararam do sexo feminino, com idade entre 29 e 51 anos. As participantes P3 e P7 atuavam na turma do berçário, P4 e P5 na de maternal I e P1, P2, P6 e P8 nos maternais II. Ressalta-se que P7, do berçário, aos 51 anos de idade, afirmava que sempre escolhia essa turma por não conseguir falar por muito tempo, devido a um problema na voz, e segundo ela na turma do berçário conseguia falar menos.

O grupo de professoras era todo formado em Pedagogia à exceção de P8 que tinha o Normal Superior e P7 que possuía o Magistério. Como se vê a formação atendia ao disposto na lei uma vez que a LDB Nº 9.394/96 prevê no Artigo 62 que a formação de docentes para atuar na educação básica deve se fazer em nível superior, em curso de licenciatura, admitindo-se como formação mínima para o exercício do magistério na educação infantil e nos 5 (cinco) primeiros anos do ensino fundamental, a oferecida em nível médio na modalidade normal. Em termos de formação para o trabalho com o tempo integral, elas destacaram encontros pedagógicos e os módulos II (estudos obrigatórios realizados pela própria escola), oficinas e planejamento com o supervisor pedagógico. Apenas uma, a P6, informou ter feito o Curso de Educação Integral Integrada.

Das oito professoras quatro eram efetivas e as outras contratadas. O tempo de experiência era diversificado, na educação infantil e no tempo integral variava dos trinta e cinco dias aos dezenove anos e na atual instituição de trinta e cinco dias a dezessete anos. Essa variação é um fator que, se bem explorado, pode proporcionar significativa troca de conhecimentos e experiências nas reuniões de estudos e planejamentos. 
A partir da discussão proposta nos questionários se buscou identificar os conceitos de educação integral das professoras e analisar como, na visão delas, a extensão da jornada escolar das crianças traria implicações para o processo ensino-aprendizagem.

Pelos depoimentos evidenciou-se que nem todas conseguiam conceituar educação integral. $\mathrm{P} 1, \mathrm{P} 2$ e $\mathrm{P} 7$, por exemplo, se referiram ao mesmo como se fosse apenas permanecer mais tempo na escola com atividades complementares. Embora os conceitos sejam relacionados, não são idênticos, pois como afirma Gadotti (2009) a educação integral referese à formação omnilateral do ser humano, de forma ampla, com qualidade social que vai além da extensão da carga horária.

Ficou perceptível que as participantes faziam relação da educação de tempo integral com a extensão da carga horária e a permanência por mais tempo na escola, mas não a relacionaram ao desenvolvimento integral da criança. Afirma Gadotti (2009) que a ETI possui a dimensão quantitativa que se refere a mais tempo na escola, ao tempo cronológico, à jornada escolar do aluno, mas também a qualitativa que diz respeito à formação ampla do ser humano e essas dimensões são inseparáveis. Menezes (2009) ressalta que a ampliação da jornada escolar se associa à concepção de centralidade da escola no que tange ao processo ensino aprendizagem que só faz sentido se tiver por fim reforçar a centralidade do aluno no sistema educacional.

Ao longo dos anos de funcionamento da CEMEI X ocorreram poucas mudanças estruturais para melhor atender o tempo integral, elas apontaram adaptação de banheiros, cobertura de um espaço para aulas de educação física, pois a quadra não era coberta, montagem da sala de recursos, escovódromo e biblioteca. A biblioteca só começou a ser criada em 2015, através da iniciativa de uma professora que, por problemas de saúde, estava em desvio de função.

Para crianças que permanecem na escola nos dois turnos, a interação entre os professores que trabalham com as turmas torna-se uma necessidade. Nesse aspecto, P1 destacou que "no início do ano é feita uma combinação entre professores e supervisores, primeiro ocorre o planejamento do matutino, deixando este para o professor do vespertino reforçar de forma lúdica, nas competências do vespertino”. Segundo elas, após o planejamento do turno matutino é que a supervisora planeja com a colega do vespertino, e esta passa para as professoras desse turno o que deve ser trabalhado em forma de oficinas. Destacaram, ainda, que ocorre interação por meio dos supervisores, nas conversas por telefone entre as professoras e nas reuniões de módulo II e planejamento.

Na prática pedagógica, algumas demonstravam segurança na condução do trabalho, outras como P6, por exemplo, afirmava não realizar o momento da rodinha na chegada sob alegação de 
não saber cantar, nem de mediar a interação com as crianças, quando possível delegava esse momento à auxiliar de classe ou substituía por uma atividade mais simples de coordenar.

$\mathrm{Na}$ realização das atividades curriculares se percebeu a fragmentação do trabalho quando destacaram que, no turno vespertino, aconteciam oficinas relacionadas aos conteúdos trabalhados no turno matutino. $\mathrm{P} 4$ especificou informando que "pela manhã: linguagem oral e escrita, filosofia e matemática, à tarde: movimento, música, contação de história, arte, oficina de sucata e psicomotricidade.” Como trabalhar a linguagem oral na educação infantil sem recorrer à literatura, à música, ao movimento? Depreende-se que de algum modo elas devem recorrer a essas áreas, mesmo assim esse discurso contribui para robustecer a ideia da existência de um processo de fragmentação na escola.

Conforme Gadotti (2009), se o que se propõe é a integralidade, o projeto pedagógico não pode ocorrer de forma que as áreas de Linguagem oral e escrita e de Matemática estejam dissociadas da educação emocional e da formação para a cidadania. O autor acrescenta que há de se ter cuidado quando se fala de educação integral para não se confundir esse conceito com iniciativas que visam mais a ocupar o tempo das crianças com atividades chamadas culturais, mas que pouco contribuem com o projeto educacional das escolas. Paro (2009, p.17) afirma que "o homem se apropria de toda cultura produzida em outros momentos históricos, e assim ele se faz histórico. Enfim, a essa apropriação da cultura, nós chamamos de educação, agora em sentido mais amplo, muito mais rigoroso, muito mais complexo”. E, segundo ele só assim podemos falar em educação integral.

No que diz respeito às implicações da política de educação de tempo integral para o processo ensino aprendizagem, todas ressaltaram que é importante, mas destacaram a desmotivação das crianças e o cansaço de permanecerem o dia todo na escola que comprometem a concentração e a aprendizagem. P1, P7 e P8 afirmaram que os alunos não aprendem melhor com a ampliação da jornada escolar. Segundo as outras professoras, muitos pais acham que educação infantil é apenas para brincar. Elas apontaram ainda a escassez de recursos, o mal aproveitamento dos que existem, a dificuldade de reconhecimento da família, a distância do convívio familiar e a carência afetiva das crianças.

Esses fatores não podem ser negligenciados sob pena de não se alcançar a aprendizagem desejada. Vale ressaltar que, mesmo que a família deixe o filho na escola de tempo integral pela razão de não poder dar a assistência devida, apesar de a participação da família ser indispensável, essa argumentação ou qualquer outra, não pode justificar a não realização por parte da escola de um trabalho bem feito em favor de todas as crianças. 
Conforme os dados, pode se afirmar que para elas a educação de tempo integral tem potencial para melhorar a aprendizagem e o desenvolvimento, no entanto falta estrutura, recursos e profissionais capacitados para que isso aconteça. E se realmente faltam essas condições, torna-se mais complicado desenvolver um trabalho interessante e significativo. Elas argumentaram que o aspecto cognitivo relacionado aos conteúdos não se desenvolve tanto, mas a parte de socialização melhora muito com a extensão da jornada escolar das crianças.

Coelho (2009) evidencia que, na perspectiva de educação integral, a pergunta que se deve fazer é se vale a pena ampliar o tempo dessa escola que aí está. Para ela antes é preciso investir num conceito de educação integral que supere o senso comum e leve em conta toda a integralidade do ato de educar, não precisando assim levantar a bandeira do tempo integral, pois para se fazer a educação de fato integral, esse tempo maior necessariamente terá que ser levado em conta. Gadotti (2009, p.51) destaca que a ampliação da jornada escolar das crianças exige imaginação, muita vontade política e integração de programas governamentais que transformem a escola em "centro formativo e de referência dos direitos de cidadania da população", envolvendo todo o entorno, ampliando a cultura para além dos muros escolares.

\section{Considerações Finais}

Com base na pesquisa pode afirmar-se que o trabalho pedagógico na escola de tempo integral ocorre demarcado pela falta de recursos humanos e materiais, pela falta de estruturação das instituições e pela pouca formação específica dos professores. Desse modo, o processo de precarização constitui-se em uma das causas da fragilidade na implementação de políticas dessa natureza e, consequentemente, do processo ensino-aprendizagem. Por outro lado, embora seja reconhecido como fato, não se justifica sua utilização para o desenvolvimento de um trabalho de má qualidade, visto que a educação integral pressupõe relevância social, cultural e científica.

Considera-se que no CEMEI X da cidade de Janaúba-MG a educação de tempo integral, embora não lhe seja exclusiva, da forma como estava sendo trabalhada acarretava, na perspectiva das professoras, implicações que afetavam o processo ensino aprendizagem, tais como: cansaço dos alunos, falta de estrutura e de recursos, ausência dos pais e carência afetiva das crianças. Em contrapartida apesar de não ser perceptível se a permanência por mais tempo na escola implicava em maior aprendizagem e desenvolvimento cognitivo representava aspecto relevante no avanço das crianças na dimensão da socialização. 
Reflexões em torno da educação integral ou da escola de tempo integral geram possibilidades de discussões diversas como, a carga horária e as atividades desenvolvidas, a formação docente e dos demais profissionais, a estrutura das instituições e dos demais recursos, a formação global da criança e da participação da família, entre outros aspectos.

Ressalta-se finalmente a relevância de realização de investigações em torno dessa política educacional que tem se evidenciado na agenda nacional em projetos e programas de sucessivos governos nas diferentes instâncias federativas.

\section{Referências:}

AZEVEDO, Joanir G. de. Fazer com paixão sem perder a razão - Retalhos de uma experiência em escola pública de tempo integral. Rio de Janeiro: DPeA, 2003.

BRASIL. Plano Nacional de Educação. Lei nº 13.005, de 25 de junho de 2014.

BRASIL. Ministério da Educação secretaria de educação básica e Diretoria de currículos e educação integral. Manual operacional de educação integral. Brasília/DF, 2013. https://doi.org/10.22409/movimento2003.v0io8.a20809

BRASIL. Portaria Normativa Interministerial $n^{\circ} 17$ de 24 de abril de 2007. Dispõe sobre o Programa Mais Educação. Diário Oficial da União, 26 abr. 2007.

BRASIL. Lei $\mathbf{n}^{\mathbf{0}}$ 9394/96 de 20 de Dezembro de 1996: Lei de Diretrizes e Bases da Educação. MEC:Brasília, 1996. https://doi.org/10.15628/rbept.2009.2954

BRASIL. Constituição Federativa do Brasil. Brasília-DF. Senado Federal. 1988.

CAVALIERE, Ana Maria Villela. Escolas de tempo integral: uma idéia forte, uma experiência frágil. In: CAVALIERE, Ana Maria Villela; COELHO, Lígia M. C. da Costa (Orgs.). Educação brasileira e (m) tempo integral. Petrópolis, RJ: Vozes, 2002. https://doi.org/10.24824/978854441844.4

CEMEI “X”. Projeto Político Pedagógico. Janaúba-MG, 2015.

CHAVES, Miriam Waidenfeld. Educação integral: uma proposta de inovação pedagógica na administração escolar de Anísio Teixeira no Rio de Janeiro dos anos 30. In: CAVALIERE, Ana Maria Villela; COELHO, Lígia M. C. da Costa (Orgs.). Educação brasileira e (m) tempo integral. Petrópolis, RJ: Vozes, 2002. https://doi.org/10.24824/978854441844.4

COELHO, L. M. C. C. (Org.). Educação integral em tempo integral: estudos e experiências em processo. Petrópolis, RJ: FAPERJ, 2009.

COELHO, Lígia M. C. da Costa. Formação continuada do professor e tempo integral: uma parceria estratégica na construção da educação integral.. In: CAVALIERE, Ana Maria Villela; COELHO, Lígia M. C. da Costa (Orgs.). Educação brasileira e (m) tempo integral. Petrópolis, RJ: Vozes, 2002. https://doi.org/10.24824/978854441844.4 
GADOTTI, Moacir. Educação integral no Brasil: inovações em processo. São Paulo: Editora e livraria Instituto Paulo Freire, 2009.

GALLO, Silvio. A educação integral numa pespectiva anarquista. In: CAVALIERE, Ana Maria Villela; COELHO, Lígia M. C. da Costa (Orgs.). Educação brasileira e (m) tempo integral. Petrópolis, RJ: Vozes, 2002. https://doi.org/10.24824/978854441844.4

KUHLMAN, Moysés Junior. Infância e Educação Infantil: uma abordagem histórica. $5^{\text {a }}$ ed. Porto Alegre-Mediação, 2010.

MACHADO, Flora Prata. Escola de horário integral: dia-a-dia concretizando utopias. In: CAVAliERE, Ana Maria Villela; COELHO, Lígia M. C. da Costa (Orgs.). Educação brasileira e (m) tempo integral. Petrópolis, RJ: Vozes, 2002. https://doi.org/10.24824/978854441844.4

MAURÍCIO, Lucia Velloso. Permanência do horário integral nas escolas públicas do Rio de Janeiro: no campo e na produção escrita. In: CAVALIERE, Ana Maria Villela; COELHO, Lígia M. C. da Costa (Orgs.). Educação brasileira e (m) tempo integral. Petrópolis, RJ: Vozes, 2002. https://doi.org/10.24824/978854441844.4

MENEZES, Janaína S. S. Educação integral e tempo integral na educação básica: da LDB ao PDE. In: COELHO, Lígia Martha C. da Costa (org.). Educação integral em tempo integral: estudos e experiências em processo. Petrópolis, RJ: DP et Alii; Rio de Janeiro: FAPERJ, 2009. https://doi.org/10.1590/s1413-24782017227170

OLIVEIRA, Zilma de Moraes Ramos de. Educação Infantil Fundamentos e métodos $-7^{\mathrm{a}}$ edição - São Paulo: Cortez, 2011.

PACHECO, Suzana Moreira. Educação integral, indicadores sociais e aprendizagem escolar. In: MUFARREJ, Mônica (coord.) ; BRAGA, Fernanda . (coord.). Educação Integral. Rio de Janeiro: Salto para o futuro, 2008. https://doi.org/10.4016/18878.01

PARO, V. H. Educação integral em tempo integral: uma concepção de educação para a modernidade. In: COELHO, L. M. C. (Org.). Educação integral em tempo integral: estudos e experiências em processo. Rio de Janeiro: FAPERJ, 2009. https://doi.org/10.11606/d.48.2014.tde-17122014-103428

PREFEITURA DO MUNICÍPIO DE JANAÚBA-MG. Lei $\mathbf{n}^{\mathbf{o}} \mathbf{1 . 5 8 9}$ de 08 de abril de 2004. Disponível em: https://janauba.mg.gov.br/legislacao/leis/2004-1589.pdf. Acesso em: 10/11/2015. https://doi.org/10.22238/rc24482692v15n22017p317a346

SOUZA, Ediléia Alves Mendes. Práticas Pedagógicas de qualidade na educação infantil em escola de tempo integral: visão de professores. (Dissertação de Mestrado) FE/UnB. Brasília-DF. 2012. https://doi.org/10.26512/2015.05.d.19166 